\title{
Monetary Valuation of Carbon Storage of the Forests: A Case of the Örümcek Forest in Turkey
}

\author{
Batuhan Ateş Yılmaz* (D), Mehmet Mısır (iD \\ Karadeniz Technical University, Faculty of Engineering, 61080 Trabzon, Turkey
}

\begin{abstract}
Global climate change has become more important than ever in last decades. Increased concentration of greenhouse gases (e.g. methane, carbon dioxide, nitrous oxide, etc.) in the atmosphere is considered as the primary cause of global warming which impacts and changes the global climate. Among the greenhouse gases, the effect of carbon dioxide $\left(\mathrm{CO}_{2}\right)$ on global warming is significantly higher than any other greenhouse gases mainly due to its abundance in the atmosphere. It has been determined by the international global climate organizations that the most effective way to combat climate change is to reduce the $\mathrm{CO}_{2}$ concentration in the atmosphere. Forests as terrestrial ecosystems have an important role in the storage of $\mathrm{CO}_{2}$. In recent decades, the importance of the carbon storage capacity of the forests has been increasing regarding with economic value of carbon storage function. Therefore, the monetary valuation of the carbon stored by the forests has become an extremely important issue. In this study, it was aimed to calculate the carbon storage capacity of a sample forest and estimate its economic value. The study was implemented in Örümcek Forest Enterprise Chief(FEC) located in the city of Gümüşhane in Turkey. The amount of carbon storage was calculated by using the allometric carbon models previously developed for tree species exist in the study area. Then, the economic value of carbon storage was estimated based on the amount of forest products extracted from the FEC between 2005 and 2017, the unit sale prices of the products, and total costs of associated activities over the years. The results indicated that the economic value of carbon stored by the forests was found to be 40.2 TRY per ton. Even though this value cannot be generalized and it is valid specifically for the forest and economic conditions in Örümcek FEC, the results in general highlight the significance of the carbon storage capacity of the forests in terms of their economic assess, which is important for the forestry sector in many countries as well as in Turkey.
\end{abstract}

Keywords: Valuation of carbon storage, Ecosystem services, Climate change, Örümcek Forest

\section{Introduction}

As the population growth rate, urbanization and industrialization has increased in the world, the demand for natural resources has increased in many countries. While fulfilling these increasing demands, various problems take place such as global climate change, air pollution, degradation of forest ecosystems, desertification, and impacts on biodiversity. Global climate change is considered as one of the most important problems that human beings face in the last century (Yilmaz, 2018). A long-term change in the average weather patterns mainly driven by the increase in Earth's global surface temperature which refers to global warming in general. The global warming occurs as a result of the greenhouse effect of the many gases that are emitted into the atmosphere mostly due to the human activities. In last decades, the ratio of greenhouse gases has dramatically increased in the atmosphere. As a result of global warming, the process that occurs with the change of other climate elements (i.e. atmospheric pressure, air movements, humidity, precipitation) that is affected by this situation is called global climate change (Kadioglu, 2004).

The atmosphere is an indispensable environment for all life forms in the world and consists of a mixture of many gases. The main gases that provide the formation of the atmosphere are nitrogen (78.08\%) and oxygen (20.95\%). Although carbon dioxide is another important gas, it has a small percentage $(0.93 \%)$ in the atmosphere. The gases that make up the rest of the atmosphere are other gases with lower proportions ( $\mathrm{Ar}, \mathrm{Ne}, \mathrm{He}, \mathrm{H} 2, \mathrm{Xe})$ (Türkeş et al., 2000). Greenhouse gases consist of gas 
compounds that have the ability to absorb heat in the atmosphere, for example; Methane $\left(\mathrm{CH}_{4}\right)$, Carbon dioxide $\left(\mathrm{CO}_{2}\right)$, Hydrofluoro-carbons (HFCs), Nitrous oxide (N2O), Sulfur-hexisfluoride ( $\left.\mathrm{SF}_{6}\right)$, and Perfluorocarbons (PFCs) (Yilmaz, 2018). $\mathrm{CO}_{2}$ has the highest proportion among the greenhouse gases and $50-60 \%$ of the anthropogenic greenhouse effect occurs due to $\mathrm{CO}_{2}$. In the last 50 years, the concentration of $\mathrm{CO}_{2}$ in the atmosphere has been constantly increasing with a fast trend compared to the previous centuries (NOAA/ESRL, 2013).

Today, the concentration of $\mathrm{CO}_{2}$ in the atmosphere is at the highest level measured in over 800,000 years.
Figure 1 shows the global average $\mathrm{CO}_{2}$ concentrations in the atmosphere over the past 800,000 years. Within continuous fluctuations in $\mathrm{CO}_{2}$ concentrations in this period, rising and falling $\mathrm{CO}_{2}$ periods coincide with the beginning of ice age (low $\mathrm{CO}_{2}$ ) and formation of glaciers (high $\mathrm{CO}_{2}$ ). These periodic fluctuations are caused by changes in Earth's orbit around the sun called Milankovitch cycles. The Industrial Revolution and the use of fossil fuels significantly increased the emissions of man-made $\mathrm{CO}_{2}$. However, the $\mathrm{CO}_{2}$ concentration, which is currently measured at $410 \mathrm{ppm}$, has not exceeded 300 parts per million ( $\mathrm{ppm}$ ) for more than 800,000 years (Figure 1) (Bereiter et al., 2015).

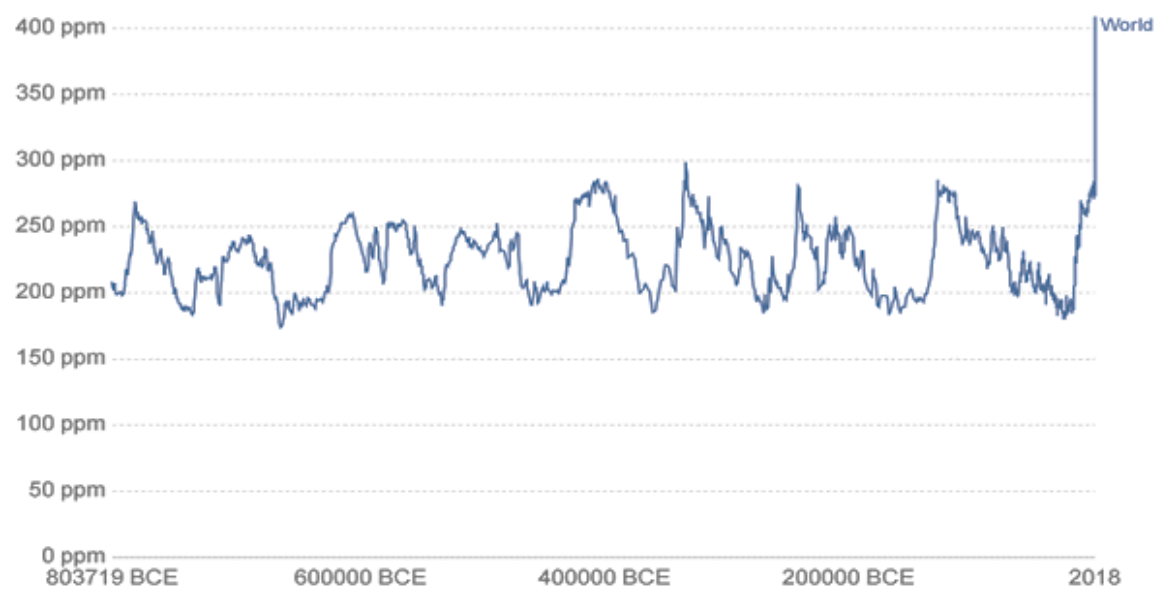

Figure 1. Historical atmospheric $\mathrm{CO}_{2}$ concentration in ppm (adapted from Bereiter et al., 2015)

\subsection{Carbon Emissions in Turkey}

The carbon value released from Turkey is approximately $1 \%$ of the total $\mathrm{CO}_{2}$ emission worldwide. This percentage is in line with the average annual $\mathrm{CO}_{2}$ emission of 6.07 tonnes per person which is slightly less than the average annual $\mathrm{CO}_{2}$ emission per person in the world (Güngör et al., 2010). While total carbon emission in the world was estimated as $151.5 \mathrm{Mt}$ in 1990, it reached up to $520.9 \mathrm{Mt}$ in 2018 which clearly proofs that carbon emission value has been going up in recent years (TUIK, 2018). Many international agreements such as Kyoto Protocol and Paris Agreement have been signed in relation to climate change yet the climate change is still a growing global problem. On the other hand, there are increasing public movements and political activities in order to improve the existing agreements and become a carbon neutral environment.

\subsection{Carbon Credits}

The carbon market is defined as the market where greenhouse gas emission reductions (credits) that cause global warming and greenhouse gas emission rights are traded (UNFCCC, 2012). In 2017, global emission allocations and offset trading exceeded $6.3 \mathrm{Gt}$ which was $5 \%$ more than the volume traded in 2016. The economic value of transactions in the carbon markets has increased by $22 \%$ and reached to 41 billion euros. Despite the increase, compared to the stagnant market in 2016, it remains below 49 billion euros in 2015 (Table 1) (Reuters, 2018).

Table 1. Volume of global carbon markets (Reuters, 2018)

\begin{tabular}{lccccccc}
\hline & \multicolumn{2}{c}{2015} & \multicolumn{2}{c}{2016} & \multicolumn{2}{c}{2017} & $\%$ \\
\cline { 2 - 8 } & Mt & $€$ million & Mt & $€$ million & Mt & $€$ million & {$[€ \mathrm{~m}]$} \\
\hline Europa & 5073 & 38358 & 5245 & 27744 & 5121 & 30760 & 74 \\
CERs & 100 & 87 & 49 & 63 & 21 & 23 & \\
North America & 1042 & 10633 & 544 & 5070 & 952 & 9328 & 23 \\
South Korea & 1.2 & 11 & 5 & 62 & 7 & 140 & \\
Chine pilot systems & 70 & 160 & 113 & 202 & 127 & 204 & \\
New Zealand & & & 76 & 774 & 810 & 870 & 2 \\
Other Markets & 2 & 4 & & & & & \\
\hline Total & 6288 & 49253 & 6031 & 33915 & 6309 & 41325 & \\
\hline
\end{tabular}




\subsection{Emissions Trading}

The carbon market is used as the term because it constitutes a large part of carbon dioxide and other greenhouse gases are also converted as carbon equivalents. Thus, the carbon market, which generally represents all greenhouse gases, is considered as an important tool in reducing emissions with the condition of working in line with market conditions. The carbon market punishes those who emit more than the limit set to reduce emissions, while those that emit less are rewarded, thereby managing available resources at the lowest cost. In addition, by converting the priced pollution units into the property rights, carbon market enables carbon to be traded all over the world, and a properly functioning carbon market encourages businesses to release less greenhouse gases by using clean technology (ICAP, 2019).

The recent report of the International Carbon Action Partnership reveals that emissions trading systems (ETSs) are strengthening across the world (ICAP, 2019). The interest of countries in ETSs to meet their commitments under the Paris Agreement has increased in recent years. 20 emission trading systems covering 27 jurisdictions worldwide are active (RGGI, California, Nova Scotia, Quebec, Massachusetts, EU, Switzerland, Kazakhstan, Korea, New Zealand, 8 pilot regions of China, Tokyo and Saitama) operate in economies that make up 40\% of global GDP. There are 6 jurisdictions (Mexico, Colombia, New Jersey, Virginia, Ukraine, China) planned to be operational in the next few years, and ETSs is planned to be established in 12 jurisdictions (Washington, Oregon, New Mexico, Brazil, Chile, Turkey, Thailand, Vietnam, Indonesia, Japan, Russia, Taiwan). On the other hand, it is expected that the local carbon market in China, which is expected to be the largest company in the world, will almost double the share of global emissions regulated by emissions trade between 8 and 14\% (ICAP, 2019).

The main ETSs in sectoral aspect can be listed as energy, internal aviation, transportation, construction, waste, and forestry. In forestry sector, emissions and removals due to forest land use activities such as forest management, harvesting, deforestation, reforestation and afforestation are taken into consideration. Looking at the share of the forestry sector in the current emission trading systems, it is seen that it is listed in the last ranks (ICAP, 2019).

\subsubsection{Mandatory Carbon Markets (Flexibility Mechanisms under the Kyoto Protocol)}

With the flexibility mechanisms which are defined in the Kyoto Protocol as Clean Development Mechanism (CDM), Joint Implementation (JI), and Emission Trading (ET), countries are able to reduce emissions at low cost. According to the Kyoto Protocol, the ET and JI mechanisms can be made between Annex-I countries, and the CDM between Annex-I and non-Annex-I countries (Türkeş et al., 2000).

With CDM mechanism, which is regulated by Article 12 of the Protocol, it is aimed that Non-Annex-I countries contribute to greenhouse gas reduction in line with the sustainable development principle. In order to realize the emission reduction commitment of the parties included in Annex-I, they will obtain a "Certified Emission Reductions-CER" as a result of the project activities to be carried out in countries other than AnnexI. JI mechanism, regulated by Article 6 of the Protocol, earns the "Emission Reduction Unit-ERU" from projects aimed at reducing greenhouse gas emissions or removing greenhouse gases through sinks, provided that the necessary conditions are met between Annex-I countries credits are deducted from the total target. Finally, with ET mechanism, which is regulated by Article 17 of the Protocol, any party country included in Annex-I can trade a portion of the emission reduction amount specified in Annex-B. In other words, the country that makes a reduction more than the amount of promised emissions can sell this additional reduction in its release to another Annex-I country.

\subsubsection{Voluntary Carbon Markets}

Voluntary Carbon Markets (VCMs) is a market created to facilitate the voluntary reduction and balancing of greenhouse gas emissions resulting from the activities of individuals, institutions and organizations, companies and non-governmental organizations. This process is similar to the Flexibility Mechanisms that are mandatory under the Kyoto Protocol. The fact that the public is not included in this process within the scope of national obligations is one of the most important differences that distinguish VCMs from the mandatory processes under the Kyoto Protocol (Hamrick and Gallant, 2017).

Stakeholders of the VCMs, which are not legally binding, aiming to reduce emission reduction costs and whose participants may be private sector, international organizations, public institutions and third parties, are as follows;

- Project owners (can prepare emission reduction projects and sell their certificates)

- Wholesalers (selling major reduction certificates in their portfolios),

- Retailers (selling small amounts of certificates to individuals or organizations)

- Brokers (although they do not have release certificates, they act as intermediaries by bringing together those selling emissions certificates and sellers). The historical market-wide voluntary offset transaction volumes are indicated in Figure 2 (Hamrick and Gallant, 2017). 


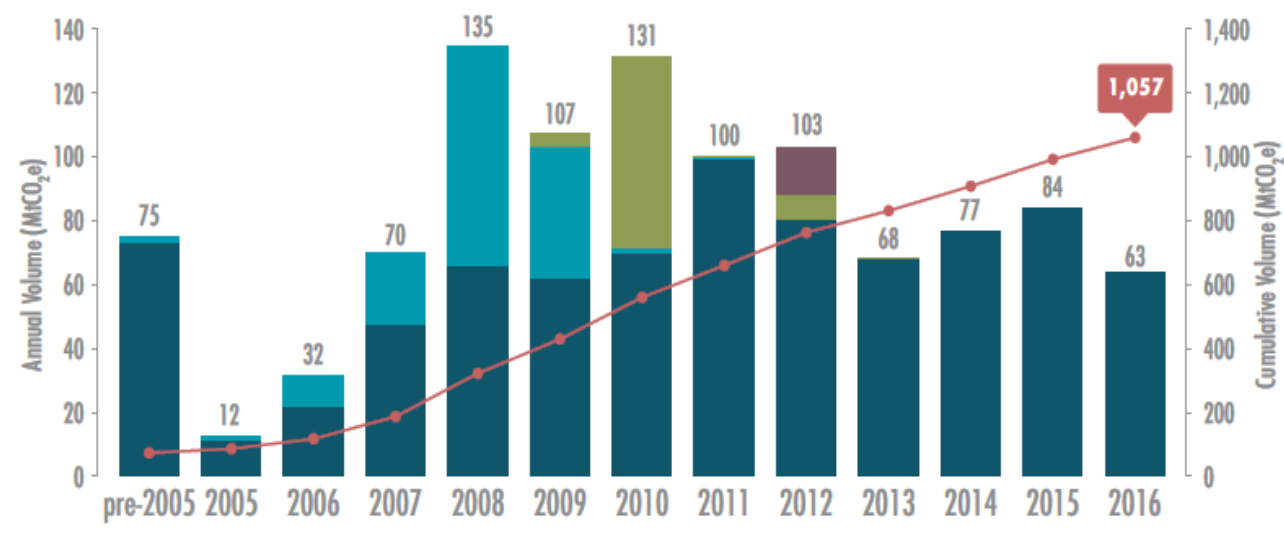

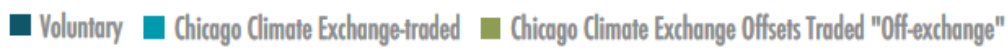

口 Pre-Compliance Volume $\rightarrow-$ Cumulative Volume

Figure 2. The annual voluntary offset transaction volumes (adapted from Hamrick and Gallant, 2017)

The forest ecosystem plays crucial role in the global carbon cycle. It stores $80 \%$ of all aboveground terrestrial organic carbon and $40 \%$ of all underground terrestrial organic carbon (IPCC, 2001). In addition to the carbon stored in forest ecosystems today, the monetary value of this carbon has become increasingly important. "Carbon Markets" and "Carbon Economy", which are developed in the last 10-15 years in the world, clearly show this increasing interest. There are limited number of studies about carbon sequestration in Turkey (Gulsunar, 2011; Bulbul, 2012; Erkut, 2013). In previous studies, the carbon storage capacity of forests has been investigated but its economic value has not been calculated. The aim of the study was to calculate the economic value of the carbon storage which reveals one of the important economic benefits of forests besides their ecological benefits.

\section{Material and Methods \\ 2.1. Study Area}

The study was carried out in Örümcek FEC located in Torul Forest Enterprise Directorate (FED) in the Trabzon Forest Regional Directorate (FRD) in northeast of Turkey. The Örümcek FEC is positioned between $40^{\circ} 26$ '27 "- 40 43' 39" north latitudes and $38^{\circ} 54$ ' $27^{\circ}$ "- $39^{\circ} 08^{\prime}$ $20^{\prime \prime}$ east longitudes. Figure 3 indicates the location of the FEC and land use types in the study area. The forests in the Örümcek FEC is managed under seven forest management classes considering economic, ecological and sociocultural functions according to the most recent forest management plan of 2016.

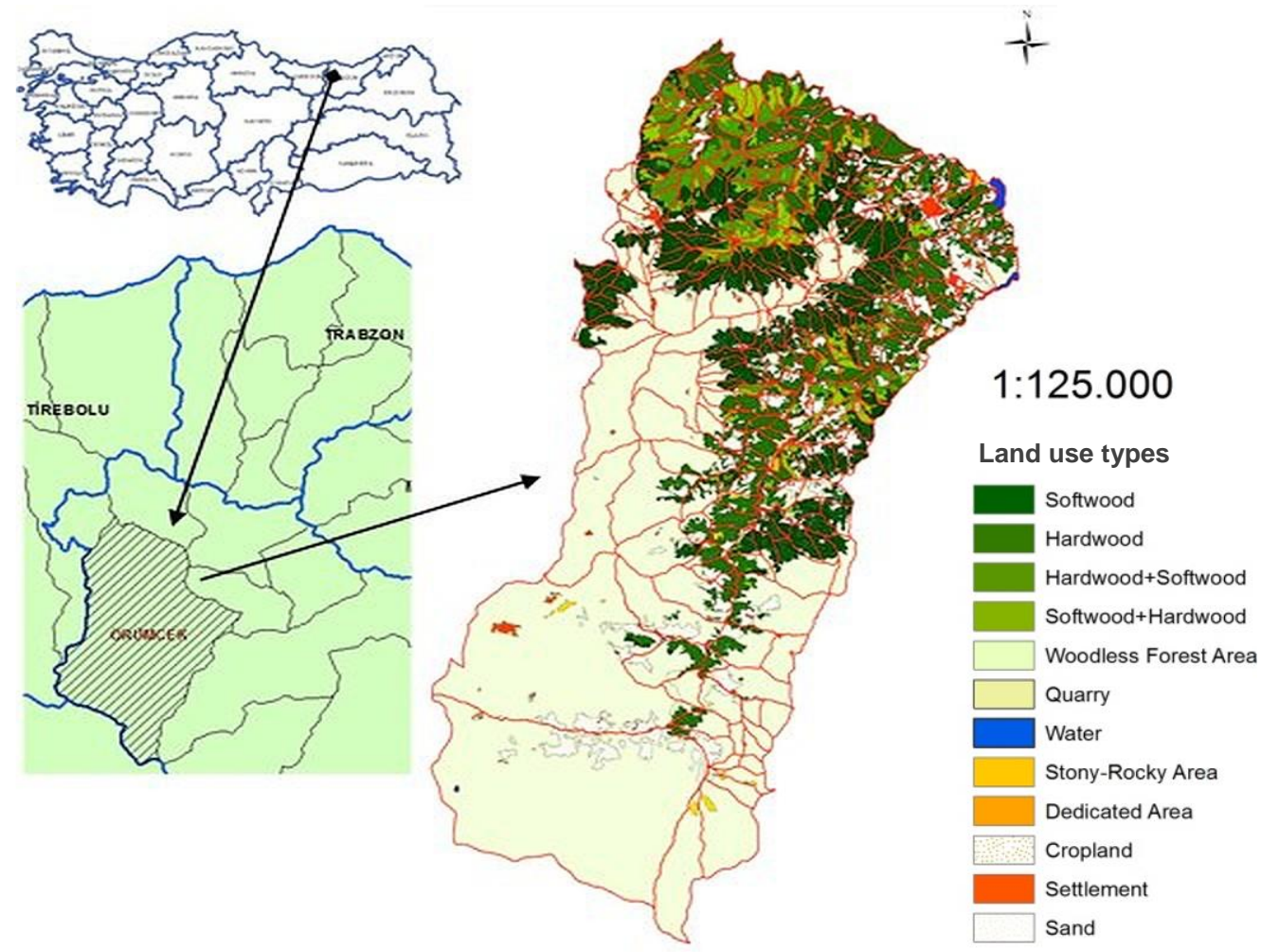

Figure 3. The location and land use map of Örümcek FEC 


\subsection{Monetary Valuation of Carbon Storage}

In order to calculate the economic value of the carbon storage, firstly the amounts of carbon storage for the forest stands located in the study area were determined based on the forest inventory data obtained by conducting the field studies in 2015. The total amount of carbon stored in each tree is generally calculated based on the models developed as a function of tree diameter. In this study, tree diameter based allometric carbon models previously developed for various tree species were used to calculate the carbon storage of the trees (Table 2). The amount of carbon storage was calculated for each stand type in the study area. Then, carbon storage was determined for stand development stages and tree species compositions regarding with seven forest management classes existed in Örümcek FEC (Table 3).

After calculating the total amount of carbon stored in the study area, the economic value of the stored carbon was calculated depending on total amount of product to be extracted, actual sale data of the forest products, and costs of managing forests over the years. The data of stumpage sale that took place in 2017 was used to estimate the total income. The total costs of managing forests were calculated by considering the forestry activities including forest mensuration, forest protection, regeneration, rehabilitation, combating biotic and abiotic agents, administrative services, constructing and maintaining forest roads and firefighting activities, etc.

Then, the total net profit obtained as a result of the wood production activities in Örümcek FEC was calculated based on total amount of sales $\left(\mathrm{m}^{3}\right)$, sales income, and total costs. All of these necessary data from 2005 to 2017 were obtained from the records of the Torul
FED. Since the management period is estimated as 120 years, the necessary data were also required for 19502005 period and 2017-2070 period. Net Future Value formula (Equation 1) was used to project the sale incomes and costs of activities in the past (1950-2005) to the year of 2005, and the incomes and cost of activities in the future (2017-2070) to the year of 2070.

$V_{n}=\left(V_{0}\right) x(1,0+p)^{n}$

$V_{n}:$ Net Future Value (TRY)

$V_{o}:$ Net Present Value (TRY)

$p$ : Annual discount rate (\%)

$n$ : Time (year)

During the calculations, 5\% was used as the annual discount rate, which maximizes the net present value of the objective function for the products obtained from forests. In order to discount the expenses somehow, the annual average interest rate of $5 \%$ has been added to the solution. (Görücü, 2001). In the next step, total net profit of the products for the management period of 120 years was calculated by using Equation 2. Finally, the economic value of the carbon per tonne was calculated by dividing total net profit of the products by the total carbon stored in the forest management class where wood production occurred.

$N P_{n}=\sum_{i=0}^{n} A t-C t$

$N P_{n}$ : Total net profit (TRY)

At : Total income (TRY)

$C t \quad$ : Total costs (TRY)

Table 2. Allometric carbon models used in the study

\begin{tabular}{lll}
\hline Tree Species & Carbon Models & Sources \\
\hline Spruce & $0.033 \mathrm{xd}^{2.43}$ & Misir et al.,2011 \\
Beech & $0.025672 \mathrm{xd}^{2.775}$ & Misir et al., 2013 \\
Scots Pine & $\left(0.413 \mathrm{xd}^{2}\right)-28.36$ & Yavuz et al., 2010 \\
Fir & $0.109 \mathrm{xd}^{2.092}$ & Misir et al., 2012 \\
Oak & $\left(0.0466 \times \mathrm{d}^{2.574}\right) \times 1.0353$ & Makineci et al., 2011 \\
European Black Pine & $5.927536 \times 1.155611^{\mathrm{d}}$ & Guner and Comez, 2017 \\
\hline
\end{tabular}

Table 3. Forest management classes in the study area

\begin{tabular}{cl}
\hline Forest Management & Descriptions \\
\hline A & The highest amount of wood production \\
B & Nature protection \\
C & Gene protection \\
D & Nature park-1 \\
E & Nature park-2 \\
F & Soil protection \\
G & Water protection \\
\hline
\end{tabular}




\section{Results and Discussion}

Forests are terrestrial ecosystems with different externalities and they provide a wide range of benefits to society. Some of these benefits are carbon storage, soil conservation, climate regulation, recreational use, water resources protection and wildlife conservation. Many of these benefits are seen as ecosystem services that are cannot be calculated in monetary terms (Masiero et al., 2019). This study aimed to calculate the carbon storage of the forests in Örümcek FEC and estimate its economic value. Table 4 indicates the carbon storage of the forest stands calculated as kg per hectare. It was found that the forest stands mixed with Beech and Spruce had the highest carbon storage amount per unit area. On the other hand, Yellow pine stands had the lowest amount of carbon storage in the study area.

The amount of carbon storage was determined for seven forest management classes of Örümcek FEC (Figure 4). Table 5 indicates the carbon storages of stand development stages for management classes. The results indicated that the management class F $(382,619.98$ tonnes) stored the highest amount of carbon, followed by class A $(124,984.64$ tonnes). It was found that the amount of carbon stored in the entire study area was calculated as $589,575.67$ tonnes.

Table 4. The amount of carbon storages regarding with the stand types

\begin{tabular}{|c|c|c|c|c|c|}
\hline $\begin{array}{l}\text { Stand } \\
\text { Type* }\end{array}$ & $\begin{array}{l}\text { Carbon } \\
(\mathrm{kg} / \mathrm{ha})\end{array}$ & $\begin{array}{c}\text { Stand } \\
\text { Type }\end{array}$ & $\begin{array}{l}\text { Carbon } \\
(\mathrm{kg} / \mathrm{ha})\end{array}$ & $\begin{array}{l}\text { Stand } \\
\text { Type }\end{array}$ & $\begin{array}{l}\text { Carbon } \\
(\mathrm{kg} / \mathrm{ha})\end{array}$ \\
\hline Çsa3 & 250.00 & KnGnbc3 & 50961.38 & LGbc3 & 31900.92 \\
\hline Çsab3 & 5984.42 & KnLa3 & 300.00 & LGcd2 & 54845.14 \\
\hline Çsb3 & 33255.37 & KnLab3 & 12713.64 & LGcd3 & 87193.81 \\
\hline Çsbc3 & 98695.24 & KnLb3 & 30490.11 & $\mathrm{LGd} / \mathrm{a} 0$ & 18539.43 \\
\hline Çsc3 & 155466.03 & KnLbc3 & 90207.35 & LGd2 & 82880.41 \\
\hline Çscd/a & 23460.89 & KnLcd1 & 102179.18 & LGd3 & 106380.87 \\
\hline Çscd1 & 57062.09 & KnLcd2 & 116812.85 & LGnbc3 & 35162.35 \\
\hline Çscd2 & 81123.39 & KnLcd3 & 124273.28 & LKna3 & 300.00 \\
\hline ÇsLa3 & 250.00 & $\mathrm{KnLd} / \mathrm{a}$ & 26142.16 & LKnbc2 & 14798.35 \\
\hline ÇsLbc3 & 87405.38 & $\mathrm{KnLd} 2$ & 260503.00 & LKnbc3 & 65563.55 \\
\hline ÇsLcd1 & 53653.18 & Lbc3 & 42336.21 & LKncd1 & 35953.89 \\
\hline ÇsLcd2 & 105521.32 & Lc3 & 60346.88 & LKncd1/ab2 & 35621.37 \\
\hline ÇsLcd3 & 167679.61 & Lcd1 & 30735.37 & LKncd2 & 55969.76 \\
\hline GKnbc3 & 82769.62 & $\operatorname{Lcd} 2$ & 57625.13 & LKncd3 & 122064.70 \\
\hline GLbc3 & 83156.65 & Lcd3 & 83263.69 & LKnd2 & 106340.69 \\
\hline GLcd2 & 74142.35 & LÇsbc3 & 74306.16 & Mzbc3 & 7395.81 \\
\hline GLcd3 & 90485.94 & LÇsc3 & 60362.67 & MzGnab2 & 7118.71 \\
\hline Kna3 & 350.00 & LÇscd2 & 47469.45 & MzGnb3 & 23189.82 \\
\hline Knb3 & 32471.14 & LÇscd3 & 128457.78 & MzGnbc2 & 10933.63 \\
\hline Knbc3 & 97312.82 & $\mathrm{Ld} 2$ & 84517.68 & MzGnbc3 & 21657.22 \\
\hline Kncd3 & 233847.56 & $\mathrm{Ld} 3$ & 108034.40 & MzKnbc2 & 9831.67 \\
\hline KnGnab3 & 9874.60 & LGab3 & 11151.72 & MzKnbc3 & 24135.11 \\
\hline KnGnbc2 & 36069.56 & LGb3 & 20451.68 & & \\
\hline
\end{tabular}

*Kn: Beech, L: Spruce, Çs: Yellow pine, G: Fir, Gn: Hornbeam, Mz: Cypress

The amount of carbon storage was determined for seven forest management classes of Örümcek FEC (Figure 4). Table 5 indicates the carbon storages of stand development stages for management classes. The results indicated that the management class F $(382,619.98$ tonnes) stored the highest amount of carbon, followed by class A (124,984.64 tonnes). It was found that the amount of carbon stored in the entire study area was calculated as $589,575.67$ tonnes.

When considering the stand development stages, distinguished based on the $\mathrm{DBH}$ in $\mathrm{cm}$, it was found that the highest amount of carbon stored by the stands at stage c (366,277.60 tonnes), followed by the stands at stage $b$ $(138,734.82$ tonnes). The map of stand development stages in Örümcek FEC is shown in Figure 5.

The amount of carbon stored in management classes according to tree species/compositions were also calculated. As it can be seen in Table 6, the maximum amount of carbon was stored in stands with Beech + Spruce composition (145691.98 tonnes), followed by pure Spruce stands $(110,555.20$ tonnes). It was found that the least amount of carbon was stored in stands with Oak + Spruce composition (5098.45 tonnes). 


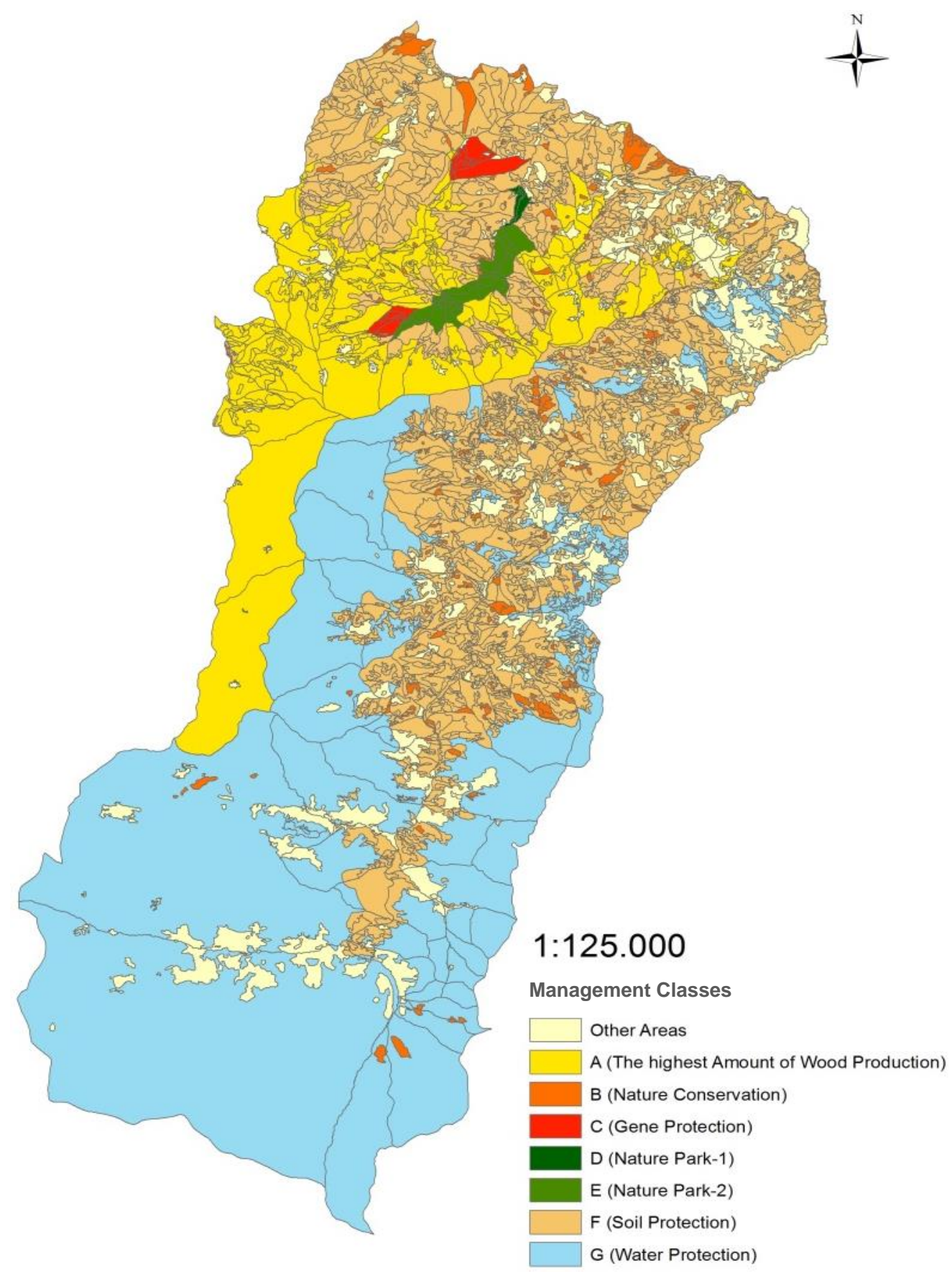

Figure 4. The map of forest management classes in Örümcek FEC

Table 5. The amount of carbon stored in management classes according to development stages (tonnes)

\begin{tabular}{ccccccccc}
\hline Development & \multicolumn{7}{c}{ Forest Management Classes } & \multirow{2}{*}{ Total } \\
\cline { 2 - 8 } Stages* & $\mathrm{A}$ & $\mathrm{B}$ & $\mathrm{C}$ & $\mathrm{D}$ & $\mathrm{E}$ & $\mathrm{F}$ & $\mathrm{G}$ & \\
\hline $\mathrm{a}$ & 6.23 & 0.00 & 0.15 & & 6.35 & 10.15 & 0.33 & 23.22 \\
$\mathrm{~b}$ & $11,388.51$ & $3,046.82$ & $2,614.07$ & 33.63 & 608.46 & $111,604.20$ & $9,439.14$ & $138,734.82$ \\
$\mathrm{c}$ & $95,952.93$ & $4,192.76$ & $12,144.83$ & $2,370.80$ & $22,378.38$ & $214,884.08$ & $14,353.81$ & $366,277.60$ \\
$\mathrm{~d}$ & $16,079.61$ & 655.16 & 552.55 & & $6,979.79$ & $49,532.22$ & 559.97 & $74,359.29$ \\
Mixed & $1,390.83$ & & 502.38 & & & 842.69 & & $2,735.89$ \\
Unproductive & 166.53 & $1,080.20$ & & 19.22 & & $5,746.65$ & 432.25 & $7,444.85$ \\
Total & $124,984.64$ & $8,974.94$ & $15,813.97$ & $2,423.65$ & $29,972.98$ & $382,619.98$ & $24,785.50$ & $589,575.67$ \\
\hline *a: BHD < 8.0 cm, b: $8.0 \mathrm{~cm}<\mathrm{BHD}<20 \mathrm{~cm}, \mathrm{c}: 20.0 \mathrm{~cm}<\mathrm{BHD}<36.0 \mathrm{~cm}, \mathrm{~d}: \mathrm{BHD}>36.0 \mathrm{~cm}$ &
\end{tabular}




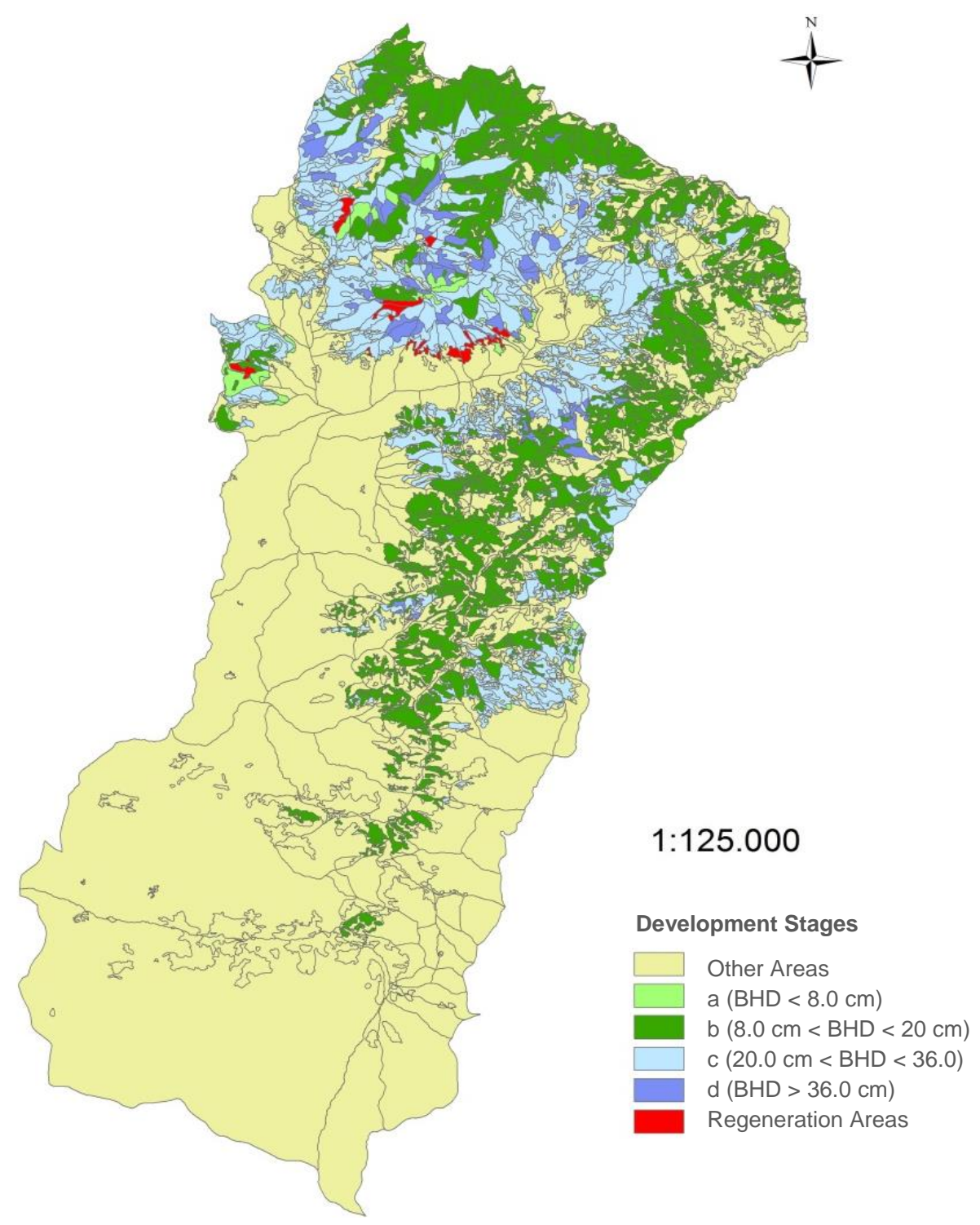

Figure 5. The map of stand development stages in Örümcek FEC

Table 6. The amount of carbon stored in management classes according to tree species/compositions (tonnes)

\begin{tabular}{lcccccccc}
\hline Tree Species/ & \multicolumn{7}{c}{ Forest Management Classes } & \multirow{2}{*}{ Total } \\
\cline { 2 - 8 } Compositions & $\mathrm{A}$ & $\mathrm{B}$ & $\mathrm{C}$ & $\mathrm{D}$ & $\mathrm{E}$ & $\mathrm{F}$ & $\mathrm{G}$ & \\
\hline Yellow Pine & $18,715.77$ & 584.32 & & & & $25,248.80$ & $6,462.30$ & $51,011.20$ \\
Spruce & $52,983.42$ & $1,790.37$ & 236.74 & 35.02 & 134.60 & $52,375.58$ & $2,999.47$ & $110,555.20$ \\
Beech & 563.10 & 41.64 & $4,154.39$ & 633.36 & $8,894.79$ & $17,313.42$ & 264.83 & $31,865.53$ \\
Oak & 37.89 & 416.76 & & 222.34 & & $3,635.79$ & 163.55 & $4,476.32$ \\
Black Pine + & $1,930.90$ & $1,868.12$ & & & & $11,897.45$ & $3,932.82$ & $19,629.30$ \\
Fir + Spruce & $1,156.53$ & & $1,091.43$ & & $2,144.91$ & $1,361.74$ & & $5,754.60$ \\
Spruce + Yellow & $12,619.31$ & 559.06 & & & & $38,837.47$ & $7,117.92$ & $59,133.76$ \\
Spruce + Fir & $17,050.36$ & & 933.59 & & $2,396.75$ & $23,443.98$ & 163.07 & $43,987.75$ \\
Spruce + Beech & $3,261.49$ & 340.18 & $1,494.47$ & $1,499.31$ & $7,538.27$ & $47,631.33$ & 657.45 & $62,422.50$ \\
Spruce + & & $1,138.22$ & & & & $12,952.73$ & 169.97 & $14,260.92$ \\
Beech + Spruce & $16,413.82$ & 552.95 & $7,863.22$ & & $8,863.66$ & $111,038.64$ & 959.68 & $145,691.98$ \\
Beech + & 244.10 & & & & & $8,984.92$ & 363.72 & $9,592.73$ \\
Oak + Spruce & & 145.21 & & & & $4,953.24$ & & $5,098.45$ \\
Oak + Hornbeam & 7.96 & $1,538.11$ & 40.13 & 33.63 & & $22,944.91$ & $1,530.71$ & $26,095.44$ \\
\hline
\end{tabular}


In the next step, total net profit of the forest products between 1950 and 2070 (for the period of 120 years) was estimated for the year of 2017 based on the total income gained from the products and associated total costs. The results indicated that total income and costs were calculated as $60,331,937.45$ TRY and 65,356,566.42 TRY, respectively. Thus, total net profit of the wood production was found to be $5,024,628.97 \mathrm{TRY}$. It was found that total estimated yield of $590180.3 \mathrm{~m}^{3}$ was able to hold 124.984,64 tonnes of carbon from the atmosphere in the study are. Therefore, the monetary value of 1-ton carbon was calculated as 5,024,628.97 / 124,984.64 = 40.2 TRY. In a similar study conducted by Ketizmen (2011), the monetary value of 1-ton carbon obtained from economically managed forests was calculated as 48.5 TRY.

According to the data obtained from The Intergovernmental Panel on Climate Change (IPCC), the unit price of 1-ton carbon varies between $\$ 5$ and $\$ 125$. Moreover, the average price of 1-ton carbon was about 14-17 Euros compared to the carbon exchanges on the international platform. Although the world carbon market values are slightly higher, the value of 1-ton carbon calculated was in the price range given by IPCC.

After financial analysis, the monetary dimensions of the carbon storage function were estimated and the results were compared with the current wood production function. The monetary equivalent of the carbon storage was computed by using the unit price of 15 euro given by the international carbon exchanges for 1 ton of carbon. The value of 1 Euro was approximately 5.5 TRY at the time of the study. According to these evaluations, it was concluded that the net profit would be 10,311,232.8 TRY if calculations are made based on carbon storage. Therefore, managing the productive forests by considering the carbon storage function instead of wood production function potentially provides more profit in the study area.

\section{Conclusions}

The forests play important role in carbon storage, which is one of the precautions that can be taken against global warming. In this study, the amount of carbon storage was calculated in a sample forest and the economic value of carbon storage function of the forest was investigated by calculating the monetary value of the carbon stored in a forest stand where wood production occurred. In the study, allometric carbon models were used to calculate the total carbon storage of the forests in the study area. It was calculated that the forest stands managed by wood production based forestry methods would generate a net profit of TL 5,024,628.97 when the expenses incurred over the years were subtracted. On the other hand, it was found that this net profit can increase by $5.286 .603,83$ TRY the stands are managed based on carbon storage. The results revealed that forests have important monetary value not only for wood production but also for carbon storage capacities and this value has an equivalent in carbon exchanges in the world.

The value of the carbon is paid to the countries as it is calculated in the carbon market which was formed by uniting against the global warming with the Kyoto Protocol and then the Paris Agreement. In order to take advantage of this cycle that exists in the world and to convert the stored carbon stock to monetary value, "Carbon Forestry" should be implemented in addition to wood production based classical forestry. To be able to carry out "Carbon Forestry", firstly, the "Carbon Function" should be included in the Nature Protection Function under the Ecological Function located in the Communiqué No. 299 (Procedures and Principles for the Regulation of Ecosystem Based Functional Forest Management Plans) in Turkey. In order to implement the "Carbon Function" effectively, it is essential to identify the specific working areas and certify the forests accordingly. In addition to these actions, financial support should be given to the carbon storage feature of the forests and related activities should be accelerated to benefit from the carbon exchanges.

\section{Acknowledgements}

I would like to thank to the Forestry Management and Planning Department in General Directorate of Forestry for their contributions.

\section{References}

Bereiter, B., Eggleston, S., Schmitt, J., Nehrbass-Ahles, C., Stocker, T.F., Fischer, H., Kipfstuhl, S., Chappellaz, J., 2015. Revision of the EPICA Dome C $\mathrm{CO}_{2}$ record from 800 to $600 \mathrm{kyr}$ before present. Geophysical Research Letters. 42(2): 542-549.

Bülbül, E., 2012. Estimation of Carbon Stock in Pure Spruce Stands of Education and Research Forest, K.T.U. MSc Thesis, Karadeniz Technical University, Trabzon. $45 \mathrm{p}$.

Erkut, S., (2013). Capacity of Carbon Stock in Pure Beech Stands of Giresun Forest District Directorate Akkuş Forest Enterprise. MSc Thesis, Karadeniz Technical University, Trabzon. 75 p.

Görücü, Ö., 2001. Modern Production Planning Approaches in Forest Enterprises and New Business Models, 1. National Forestry Congress, Foresters Association of Turkey, Ankara.

Guner, T.S., Comez, A., 2017. Biomass Equations and Changes in Carbon Stock in Afforested Black Pine (Pinus nigra Arnold. Subsp. pallasiana (Lamb.) Holmboe) Stands in Turkey. Fresenius Environmental Bulletin, 26(3):2368-2379.

Gülsunar, M., 2011. Remote Sensing Method for Forest Carbon Capacity Estimation (The Example of Düzdağ Forest Management Chiefdom). MSc Thesis, Karadeniz Technical University, Trabzon. 87 p.

Güngör, M., Saygı, N., Polat, A., Çayc1, D., Tekin, A., 2010. Green Informatics. Information Technologies 
and Communication Authority, Sectoral Research and Strategies Department. http://www.tk.gov.tr/ Yayin/Raporlar/2010/Yesil_Bilisim_SAS_TEMMU Z_2010.pdf, $110 \mathrm{p}$.

Hamrick, K., Gallant, M., 2017. Unlocking potential: State of the Voluntary Carbon Markets 2017, Forest Trends' Ecosystem Marketplace, Washington DC. 42 p.

ICAP, 2019. Emissions Trading Worldwide: Status Report 2019. Berlin: ICAP. $12 \mathrm{p}$.

IPCC, 2001. Land Use, Land-Use Change, and Forestry, Summary for Policymakers. A Special Report of the Intergovernmental Panel on Climate Change, IPCC, Geneva, Switzerland, 30 p.

Kadioglu, M., 2004. Küressel Isınma Söyleşileri. https://www.hkmo.org.tr/resimler/ekler/6a38989dc7 e433f_ek.pdf

Ketizmen, B., 2011. Investigations and Functional Comparisons on Carbon Economics in Kahramanmaraş Başkonuş Research Forest, MSc Thesis, Kahramanmaraş Sütçü İmam University, Kahramanmaraş, 94 p.

Makineci, E., Çalışkan, S., Yılmaz, H., Özdemir, E., Kumbaşl1, M., Y1lmaz, E., 2011. Determination of health status, biomass, carbon storage and fanatic properties in North Thrace grove bond oak ecosystems, TÜBİTAK-TOVAG Project Report, No: 107O750, $276 \mathrm{p}$.

Masiero, M., Pettenella, D., Boscolo, M., Barua, S.K, Animon, I., Matta, J.R., 2019. Valuing forest ecosystem services: a training manual for planners and project developers. Forestry Working Paper No. 11. Rome, FAO. 216 pp. Licence: CC BY-NC-SA 3.0 IGO.

Misır, M., Köse, S., Yavuz, H., Misır, N., Altun, L., Karahalil, U., 2011. Determining Carbon Storage Capacity of Karadeniz Technical University Education and Research Forest and Transferring to Forest Management Plan, Scientific Research Project, Trabzon.
Misır, M., Misır, N., Erkut, S. 2012. Estimations of Total Ecosystem Biomass and Carbon Storage for Fir (Abies nordmanniana S. Subsp. bornmülleriana (Mattf.)) Forests (Western Black Sea Region), Kastamonu University Journal of Forestry Faculty, IUFRO SE. 60-64.

Mısır, M., Misır, N., Ülker, C., Erkut, S., 2013. Determination of the carbon storage amount of pure Beech stands (Example of Trabzon Regional Directorate of Forestry), Scientific Research Project, Trabzon.

NOAA/ESRL, 2013. Dr. Pieter Tans, NOAA/ESRL. www.esrl.noaa.gov/gmd/ccgg/trends/

Reuters, T., 2018. Carbon market monitor 12 January 2018, Thomson Reuters Commodities Research and Forecasts.

TUIK, 2018. Greenhouse Gas Emissions Statistics, 1990 - 2018. Turkish Statistical Institute, Ankara. Turkey. http://www.tuik.gov.tr/PreTablo.do?alt_id=1019.

Türkeş, M., Sümer, U.M., Çetiner, G., 2000. Flexibility Mechanisms Under the Kyoto Protocol, Installation Journal, 52: 84-100.

UNFCCC, 2012. Report of the Conference of the Parties serving as the meeting of the Parties to the Kyoto Protocol on its eighth session, held in Doha from 26 November to 8 December, Addendum, Part Two: Action taken by the Conference of the Parties serving as the meeting of the Parties to the Kyoto Protocol at its eighth session.

Yavuz, H., Mısır, N., M., Tüfekçioğlu, A., Karahalil, U., 2010. Development of Mechanical Growth Models, Determination of Biomass and Carbon Storage Amounts for Pure and Mixed Scotch Pine (Pinus sylvestris L.) Stands in the Black Sea Region, TÜBITAK-TOVAG Project Report, No: 106O274, Ankara.

Yilmaz, B.A., 2018. Economic Analysis of Carbon Storage Amounts of Forests (Örümcek Enterprise Chief Sample). MSc Thesis, Karadeniz Technical University, Trabzon. 